\title{
ENTRE LIBERAIS E TECNICISTAS: A DIDÁTICA NAS REFORMAS DO ENSINO
}

\author{
FERNANDO BONADIA DE OLIVEIRA ${ }^{1}$ \\ ORCID: https://orcid.org/0000-0003-4627-3162
}

\begin{abstract}
RESUMO: A transformação da Didática vem sendo perseguida pela escola brasileira desde a Reforma de 1928 no Distrito Federal. Quase noventa anos depois de muitas outras tentativas de reforma, as autoridades políticas promoveram, no Brasil, um novo projeto de remodelação do ensino (Lei $\mathrm{n}^{\circ}$ 13.415/2017). A reforma atual afeta a educação nacional em todos os níveis, e, embora muitos reconheçam que seu fundamento já esteja contido em determinações oficiais anteriores, seus defensores a divulgam como uma autêntica renovação. Este artigo pretende evidenciar que a atual reforma brasileira repete impasses de reformas passadas, todas ineficazes para alterar, de forma substancial, a natureza geral da Didática tradicionalmente admitida. Nessa interpretação histórica, especial enfoque será dado à relação entre a atual reforma e a reforma escolar da ditadura (Lei nº 5.692/1971). Apontase, finalmente, a persistência temporal de certa convivência nociva entre a pedagogia liberal e o tecnicismo pedagógico no Brasil.
\end{abstract}

Palavras-chave: didática, educação brasileira, reforma do ensino, liberalismo educacional, tecnicismo.

\section{BETWEEN LIBERALS AND TECHNICISTS: DIDACTIC IN EDUCATION REFORMS}

\begin{abstract}
The transformation of didatic has been pursued by the brazilian school since the 1928 reform in Distrito Federal. It wasn't until 90 years later after many other attempts of reform, that the political authorities promoted in Brazil a new Education remodelling project (law n. 13.415/2017). The current reform affects the national education in all levels, and although many recognize that its foundation is already within former official determinations, its defensors advertise it as an authentic renovation. This article intends to evidence that the current brazilian reform repeats impasses from past reforms, all of them unable to alter substantionally, the general nature of the traditionally admitted didatic. In this historical interpretation, a special focus will be given to the relation between the current reform and the scholar reform of the dictatorship (law n. 5.692/1971). Finally, it points the temporal resistance of a certain harmful coexistence between the liberal pedagogy and the pedagogical technicality in Brazil.
\end{abstract}

Keywords: didactic, brazilian education, education reform, educational liberalism, technicality.

\section{ENTRE LIBERALES Y TECNICISTAS: LA DIDÁCTICA EN LAS REFORMAS DE LA ENSEÑANZA}

\footnotetext{
${ }^{1}$ Professor do Departamento de Teoria e Planejamento de Ensino - Instituto de Educação - Universidade Federal Rural do Rio de Janeiro (UFRRJ). Rio de Janeiro, RJ, Brasil. < fernandofilosofia@hotmail.com> Educação em Revista|Belo Horizonte|v.36|e220281|2020
} 
RESÚMEN: La transformación de la Didáctica viene siendo pretendida por la escuela brasileña desde la Reforma de 1928 en el Distrito Federal. Casi noventa años después de muchos otros intentos de reforma, las autoridades políticas han promovido en Brasil un nuevo proyecto de remodelación de la enseñanza (Ley n ${ }^{\circ}$ 13.415/2017). La reforma actual afecta la educación nacional en todos los niveles, y aunque muchos reconozcan que su fundamento ya esté contenido en determinaciones oficiales anteriores, sus defensores la divulgan como una autentica renovación. Este artículo pretende poner en relieve y evidenciar que la actual reforma brasileña repite impases de reformas pasadas, todas ineficaces para cambiar, de forma sustancial, la naturaleza general de la Didáctica tradicionalmente admitida. En esta interpretación histórica, especial relieve será dado a la relación entre la actual reforma y la reforma escolar de la dictadura (Ley $\mathrm{n}^{\circ}$ 5.692/1971). Se apunta, por fin, la persistencia temporal de cierta convivencia nociva entre la pedagogía liberal y el tecnicismo pedagógico en Brasil.

Palabras clave: didáctica, educación brasileña, reforma de la enseñanza, liberalismo educacional, tecnicismo.

\section{UM PROBLEMA HISTÓRICO}

Da República Velha à Nova República, todas as reformas de ensino que ganharam destaque na imprensa ou nos círculos intelectuais se expressaram em forma de lei. As reformas são frequentemente disparadas quando um político ou um acadêmico - ligado às bases de poder conquista uma pasta e a assume, seja a Secretaria do Estado da Educação, seja o Ministério da Educação. Tão logo convenha, por intermédio de lei, ele determina uma reforma sem dar importância ao que pensam os cidadãos e os educadores. A reforma é feita para eles, não com eles².

Esse procedimento reformador não consiste em mais um episódio de inexperiência democrática da sociedade fechada que se edificou no Brasil (FREIRE, 2002, p. 73), mas em seu episódio fundador. O alijamento da voz popular do processo de construção da versão final das reformas é a fonte que aprofunda a inexperiência democrática em amplas proporções. Os reformadores só se dão conta da existência do povo e dos educadores quando as reformas já estão em curso e todos heroicamente resistem a elas. Assim, é possível afirmar a posteriori que as alterações não trouxeram bons resultados, porque os professores e as escolas foram relutantes quanto às inovações introduzidas; os reformadores e seus sequazes saem ilesos de todo o processo de deformação da escola, e o mesmo caso se repete.

Este trabalho gravita em torno da expectativa de uma "revolução" brasileira do ensino, frequentemente afastada pelas contínuas desmobilizações provocadas por reformas distorcidas que, sob o pretexto de aprimorar, corroem a educação escolar do País. Como seria possível uma modificação radical das bases do ensino que propiciasse, de fato, a transformação da escola em seus fins, métodos e práticas? A experiência histórica deixa patente que a escola não se transformará por meio de um receituário advindo de algum intelectual distante da prática escolar, mas de uma participação de qualidade, a enredar professores, técnicos, alunos, famílias e toda a sociedade. Ao evidenciar o modo pelo qual o reformismo brasileiro vem se desenvolvendo no plano da educação, ofereceremos uma descrição de como a combinação entre liberalismo e tecnicismo pedagógico culminou sempre na incapacidade completa de ressignificar as bases do ensino e das concepções de aprendizagem. Este texto visa, em especial, demonstrar a nocividade do projeto liberal-tecnicista brasileiro no campo preciso da Didática, tanto durante a reforma escolar da ditadura civil-militar iniciada em 1964 com a Lei $\mathrm{n}^{\circ} 5.692$ (BRASIL, 1971), quanto atualmente, com as derivações da proposição do "Novo Ensino Médio", instituído pela Lei no 13.415 (BRASIL, 2017). Entendemos que a análise histórica das reformas

\footnotetext{
2 José Willington Germano (1993, p. 159) identifica, que antes da Lei no 5.692, foram feitas, na República brasileira, nove reformas do ensino, tendo sido a Lei no 4.024/61 (BRASIL, 1961) a única reforma determinada pela Constituição de 1946. Todas as demais, desde a de Benjamin Constant (1890) até a de Gustavo Capanema (1942), foram feitas por intelectuais ou políticos e recebem o nome dos líderes reformadores. 
do ensino no Brasil é essencial para a constituição de alternativas reais para a educação escolar brasileira, ainda que seja como um ponto de partida negativo, a indicar o que não se deve fazer.

Neste artigo, tendo o problema da Didática como foco, abordaremos inicialmente as reformas brasileiras dos anos 1920, especialmente a de Fernando de Azevedo no Distrito Federal e a de Sampaio Dória, em São Paulo. Em seguida, evidenciaremos as proximidades entre a remodelagem paulista de Dória e a de José Mário Pires Azanha, este último já no final dos anos 1960. Com isso, será recomposto o modelo do ideário "liberal-renovador" brasileiro em educação. A seguir, explicitaremos a combinação desse liberalismo com o tecnicismo pedagógico típico da reforma escolar da ditadura e, finalmente, à luz da análise da reforma atual, demonstraremos como a educação pública do País tem padecido ainda dessa fusão perversa liberal-tecnicista, agora em sua forma neoliberal e neotecnicista.

Cabe advertir que este texto se refere a um trabalho de política da educação brasileira, amparado nos estudos da história da educação, sem a pretensão de aprofundar pormenores intimamente ligados ao campo preciso da Didática. Alguns desdobramentos possíveis para este domínio serão indicados em nota.

\section{A REFORMA DO DISTRITO FEDERAL NO FIM DOS ANOS 1920}

O principal obstáculo imposto para o exame da atual reforma do ensino é o desconhecimento da história das reformas educacionais feitas no Brasil durante o período republicano, e não foram poucas, nem no plano federal, nem no estadual. É sempre conveniente recordar que a reforma escolar da ditadura foi a décima reforma da República (OLIVEIRA, 2017, p. 21) e, em todas elas, desde as mais remotas, realizadas ainda na década de 1920, esteve em discussão, de alguma maneira, a ambição de "renovar a escola".

Essa concepção de renovação presente no espírito reformista educacional brasileiro passou sempre pela exigência de revisão dos métodos de ensino ditos tradicionais, de modo a implicar necessariamente o campo da Didática. É despropositado e raso querer definir em poucas linhas o que se deve entender como Didática, mas é impossível deixar de reconhecer - para os fins desta explanação sobre as reformas de ensino - que tal saber (ou saber-fazer) tem historicamente se debruçado sobre temáticas implicadas nos processos de ensino, sejam eles concebidos como estratégias, finalidades, currículo ou avaliação. Se qualquer reconfiguração político-educacional mínima já afeta toda a organização do trabalho pedagógico, é no domínio da Didática que as reformas mais causam interesse. Tem sido assim, aliás, desde a República Velha.

Fernando de Azevedo (1976, p. 163), em A transmissão da cultura (1943), reserva um capítulo inteiro para narrar o intuito das reformas educacionais renovadoras propostas no Brasil republicano, estimando como marco inicial o ano de 1928, quando se deu a reforma do Distrito Federal por ele mesmo promovida. A ação reformista, nas palavras do educador brasileiro, foi nesse caso o "foco mais intenso de irradiação das novas ideias e técnicas pedagógicas" (p. 164). Instituída em forma legal pelo Decreto n. 3.281 (BRASIL, 1928), esta remodelação teria incitado outras tantas iniciativas de alcance similar, tornando-se "a primeira lei promulgada no país sobre o rádio e o cinema educativo". Em seu título IV, "do cinema escolar e do rádio", o decreto estabeleceu "que todas as escolas terão salas destinadas à instalação de aparelhos de radiotelefonia e alto-falantes" (art. 296).

Embora boa parte da reforma de 1928 se circunscrevesse à infraestrutura escolar e outras inovações técnicas, a essência do projeto que a norteava, segundo seu formulador, calcava-se em três princípios pedagógicos gerais: maior liberdade para as crianças, recurso sistemático a métodos ativos e maior atenção à originalidade pessoal dos educandos com a individualização do ensino (AZEVEDO, 1976, p. 165). Como todos sabem, Azevedo estava amparado pela concepção filosófico-educacional estadunidense de John Dewey. Essa tradição de pensamento se articulou no Brasil com as ideias de Lourenço Filho, também importante renovador de São Paulo nos anos de 1930 e 1931; encontrou respaldo, igualmente, no pensamento de Anísio Teixeira e se incorporou, enfim, aos propósitos da "reconstrução educacional do Brasil" de 1932 (AZEVEDO, 2006), que pode ser qualificada - apesar 
das deficiências de qualquer rótulo - como liberal-renovadora ${ }^{3}$. O próprio Azevedo (1976, p. 168) enalteceu, em particular, o projeto varguista de 1930, colocando a direção do presidente Vargas como impulso geral de libertação da educação brasileira de seus antigos grilhões tradicionalistas.

Guardadas as devidas proporções, quem lê Fernando de Azevedo tem a nítida sensação do leitor das últimas páginas do romance $A$ normalista, de Adolfo Caminha, quando o narrador descreve o retorno da personagem Maria do Carmo à Escola Normal republicana. Depois de uma série de acontecimentos tenebrosos, ela retoma os estudos na escola, que havia passado por uma reformulação desde o tempo do Império:

A sua presença foi como uma ressurreição. - A Maria do Carmo, hein?! Nem parecia a mesma! Houve um alarido entre as normalistas: abraços, beijos, cochichos... Até o edifício tinha-se pintado de novo como para recebê-la! O programa era outro, mais extenso, mais amplo, dividido metodicamente em Educação Física, Educação Intelectual, Educação Nacional ou Cívica, Educação Religiosa... pelos moldes de H. Spencer e Pestalozzi; o horário das aulas tinha sido alterado, havia uma escola anexa de aplicação, estava tudo mudado! A esse tempo um grande acontecimento preocupava toda a cidade. Liam-se na seção telegráfica da Província as primeiras notícias sobre a proclamação da república brasileira. (CAMINHA, 1893, p. 296-297)

Assim como passamos da educação dos moldes do império à educação de tipo republicana, baseada em Spencer e Pestalozzi, Azevedo nos retratou um movimento semelhante de passagem da escola de tipo republicano positivista para a escola nova dos primeiros tempos de Vargas no poder. Da mesma forma que da escola imperial à republicana tudo estava "alterado" e "mudado", a escola inovadora de Azevedo parecia ressurgir das cinzas do tradicionalismo.

Para o autor do Manifesto, foi a Universidade de São Paulo a primeira instituição que se voltou, no Brasil, em prol da renovação da educação brasileira. Essa universidade teria nascido, "como a Academia Platônica, na Grécia, e a universidade, na Idade Média", lançando ao Brasil homens eminentes e preocupados com os desafios da educação brasileira (Azevedo, 1976, p. 187). O protagonismo do Distrito Federal remete-nos à ambição reformadora de São Paulo na década de 1920, vivida em virtude do "surto de industrialismo" daquele período, fator determinante do deslocamento do eixo de gravidade demográfica do País (AZEVEDO, 1976, p. 167).

\section{A REFORMA DE SÃO PAULO NOS ANOS 1920 E 1960}

São Paulo ocupou um lugar tão especial na concepção de renovação de ensino que se tornou, sob certa perspectiva, um modelo de reforma educacional em todo o Brasil. Segundo Jorge Nagle (2009, p. 210), São Paulo se impôs como decisivo no âmbito das reformas já na segunda década do século; mais precisamente, desde 8 de dezembro de 1920, quando apareceu a Lei $\mathrm{n}^{\circ} 1.750$, consolidada na reforma de Sampaio Dória (SÃO PAULO, 1920). Essa reforma foi reputada como "o principal resultado do ideário que se estruturou no decorrer do segundo decênio do século XX", sustentando "o ideário de republicanização da República, de sua democratização", visando à "elevação intelectual e moral de amplas camadas da população, de formação da consciência cívico-patriótica" (NAGLE, 2009, p. 210-211).

A reforma de Sampaio Dória, bem como a reforma baiana a cargo de Anísio Teixeira, realizada por intermédio de lei, foi emblema do ardor liberal de renovação que atravessou a virada do século XIX para o século XX, constituindo, em todo o País, o "entusiasmo pela educação" e o "otimismo pedagógico", expressões eternizadas por Nagle (2009, p. 113) a fim de explicar o ideário de renovação almejado pelos setores médios da sociedade brasileira.

José Mário Pires Azanha, o principal nome da reforma do ensino paulista transcorrida entre 1967 e 1970, recorreu justamente ao esforço de Sampaio Dória para explicar as consequências

\footnotetext{
3 Apesar de liberal e renovadora, tal tendência repousava sobre uma base contraditoriamente conservadora. Sobre isso, vale a crítica de Gandini (1980, p. 59), segundo a qual os objetivos reformistas desse grupo constituíam uma espécie de "liberalismo conservador" que pretendia alcançar a renovação da educação sem romper com as bases sociais e economicamente desiguais da sociedade brasileira.
} 
políticas de sua própria reforma ${ }^{4}$, cinquenta anos depois. O reformador dos anos 1920, segundo Azanha (1987, p. 135), ao se deparar com os limites práticos da falta de verbas para ampliação do sistema educacional, reorganizou o ensino primário e transformou a obrigatoriedade da escola básica dos 7 para os 9 anos de idade, reduzindo também o curso primário de 4 para 2 anos, bem como concentrando todo o programa de formação em um baixo número de horas. Ele preferia "uma escola aligeirada" que fosse para todos a uma escola de real qualidade democrática, mas voltada para poucos. Em 1967, assinala Azanha (1987, p. 136), a história devia se repetir: Dória reformou o primário, e o mesmo devia ser feito com o ginásio ${ }^{5}$.

A reforma de Azanha foi antecedida por uma gestão que ampliou substancialmente a rede ginasial do Estado (FERREIRA, 2007, p. 43). Naquele então, era preciso enfrentar a dificuldade de acesso dos jovens não mais exclusivamente ao primário, mas à escola secundária, interposta pelos chamados "exames de admissão" que selecionavam, dentro de todo o contingente de alunos formados no primário, os escolhidos para fazer a matrícula no curso ginasial. A Secretaria de Educação do Estado de São Paulo, capitaneada por Azanha, facilitou o exame tanto quanto foi possível no fim do ano de 1967, superlotando os cursos ginasiais de alunos que no início do ano de 1968 apresentavam em sua grande maioria - dificuldades básicas de aprendizagem.

Assim como ocorreu com Sampaio Dória, um grande alarido foi provocado: muitos professores questionaram essa "democratização" muito particular do ensino que sobrecarregava o trabalhador da educação, tornava precário seu ofício e impunha aos alunos densas agonias de confinamento. Em ato de resistência, os professores levaram os alunos aprovados sem mérito no exame de admissão à reprovação no fim de 1968, correspondente ao primeiro ano do ginásio. Em resposta a isso, Azanha passou a conceder bônus por mérito (premiação) aos professores secundários que, no fim do ano de 1969, aprovassem mais alunos. A atitude era comum no primário, mas inédita no secundário (AZANHA, 1987, p. 115).

A democratização pela força da lei, tal como pretendida pelos renovadores de São Paulo, tem sua justificação nas bases mais remotas no lema maior do escolanovismo brasileiro: "a educação não é privilégio" e, enquanto for privilégio de uma minoria, a educação dita democrática será sempre mais nefasta do que desejável. Os escolanovistas enxergavam os limites estruturais da sociedade para promover a devida democratização do ensino, mas queriam realizá-la a qualquer custo: expandir a rede (maior número de matriculados) sem a ampliação da rede (alargamento das condições de atendimento). A ação política dos reformadores da linhagem liberal-renovadora, embora sobrelevasse discursivamente - o estatuto da escola renovada e dos novos métodos ativos, tendia a se atropelar na mera consecução das metas de expansão. Nessas reformas não permanece lembrança da inserção de novos métodos de ensino. Por conseguinte, os pontos principais da Didática se mantiveram sempre como portas intransponíveis para a efetiva renovação.

Nas descrições de Azanha, os professores (e, sobretudo, os professores que se diziam democráticos) resistiram à inovação pedagógica, porque se apresentavam com um perfil de "especialista em suas disciplinas"; eram antigos estudantes formados "em Faculdades de Filosofia" que, julgando-se aptos à pesquisa, tinham que se conformar com a disposição de mercado, a saber, o campo do ensino (AZANHA, 1987, p. 112). A ausência de renovações didáticas se deve, nessa lógica, ao temperamento típico do professor escolar paulista. Quem, atualmente, pode se lembrar do "método intuitivo da lição de coisas" instituído por Sampaio Dória, a única renovação didática real da qual podem se recordar os historiadores da educação? Quem, na virada do século XXI, conheceu algum princípio renovador introduzido pela reforma paulista?

\section{O SIGNIFICADO DE SÃO PAULO PARA A REFORMA ESCOLAR DA DITADURA}

\footnotetext{
${ }^{4}$ Embora a reforma tenha sido assinada por Ulhôa Cintra, então secretário da educação do governo de Abreu Sodré, foi o Diretor do Ensino Secundário e Normal da pasta, Pires Azanha, o seu principal protagonista (CURY, 2012, p. 32-33).

${ }^{5}$ Nas palavras de Azanha: "quase 50 anos depois de Sampaio Dória, a exigência democratizadora havia se deslocado do primário para o ginásio” (p. 136). 
Os "Ginásios Orientados para o Trabalho", os "Ginásios Polivalentes" e os "Ginásios Pluricurriculares" têm origem, segundo Nunes (1980, p. 152), em "interesses políticos e exigências econômicas do capitalismo periférico, que pressionavam no sentido da modernização do sistema educacional" ". O ginásio único pluricurricular foi implantado no Estado de São Paulo nos tempos da atuação de Azanha, graças a um convênio entre o MEC (cujo diretor de ensino secundário era Gildásio Amado) e a Secretaria de Educação (na época comandada por Carlos Pasquale). Esse ginásio converteu em prática os objetivos que seriam lançados na reforma escolar da ditadura: um ensino de base tecnicista, calcado no ensino de artes industriais e na compreensão de uma expansão escolar voltada para os interesses do mercado de trabalho. Na concepção posterior de Azanha (1987, p. 97), essa proposta ginasial possuía um nome "impróprio". Segundo Souza (1970, p. 73-74),

Conceitua-se o ginásio único pluricurricular como sendo a escola que se propõe a selecionar, organizar e propiciar experiências educacionais que levem o aluno a enfrentar os problemas do ajustamento pessoal e grupal específicos da adolescência e do mundo em que vive, criando, assim, condições para a integração de conteúdos formais de conhecimento e a formação de atitudes compatíveis com as exigências de nossa cultura.

A passagem acima encontra-se no texto do "Projeto de organização e implantação dos Ginásios Pluricurriculares do Estado de São Paulo", documento preparado por Rosa Vieira, Ivone Prandi, Therezinha Fram e Nathanael Pereira de Souza. Há, nesse documento, uma vinculação entre a instituição dos Pluricurriculares e os processos MEC 65.255/66 e MEC 256/66. O primeiro processo era um "convênio especial (...) para equipamento de oficinas de Artes Industriais e Salas Ambientes de Educação para o Lar em ginásios da rede oficial do Estado"; o segundo era um "convênio especial (...) para a instalação e funcionamento de um Centro de Formação e Treinamento de Professores de matérias técnicas destinadas aos ginásios que incluam orientação para o trabalho" (SOUZA, 1970, p. 62-70). Não houve qualquer registro de inovação que não fosse a formação industrial em um modelo educacional moralista e conservador, que desejava o "ajustamento pessoal e grupal específico da adolescência" e que visava promover "atitudes compatíveis com as exigências de nossa cultura". Não é de surpreender a existência dessa orientação, uma vez que toda a formulação teórica dos idealizadores dos Pluricurriculares estava sustentada em referenciais não da Pedagogia, mas da Economia ou, quando muito, da Economia da Educação (SOUZA, 1970, p. 11-12).

A iniciativa desses ginásios foi a oportunidade de se verificar, entre as paredes das escolas paulistas, a validade do projeto da ditadura para o primeiro ciclo do segundo grau. O projeto consistia em expandir a rede de ensino e converter a educação escolar, até então considerada humanista e colonial, em uma vertente de ensino altamente profissional e promotora de uma massa de trabalhadores preparada para a exploração no setor industrial. Do projeto dos ginásios paulistanos fazia parte - aliás, parte importantíssima - o projeto da escola obrigatória de oito anos, com o qual o Brasil passaria, por força de lei, de uma das taxas de escolaridade mais baixas do mundo (os quatro anos primários, conforme a Lei no 4.024/61) para uma das mais altas. São Paulo esteve na dianteira de todo o processo de tecnicização do ensino brasileiro que viria a se consagrar na Lei $n^{\circ} 5.692$.

No início de 1970, o ministro da Educação Jarbas Passarinho já acenava com as primeiras ideias do que viria a ser a reforma empreendida pela Lei $\mathrm{n}^{0} 5.692$, que acabou com a divisão entre ensino primário e ginasial, extinguindo o exame de admissão e instituindo a escolarização obrigatória de oito anos em todo o território nacional. As reportagens em São Paulo sempre incluíam felicitações ao governo paulista, que se antecipara a tais medidas (CURY, 2012, p. 81).

A educação no Estado de São Paulo, na dianteira do atraso que viria a se tornar a Lei $\mathrm{n}^{\circ}$ 5.692, é o exemplo cristalino de como os renovadores liberais historicamente se conjugaram aos

\footnotetext{
${ }^{6}$ Esses interesses foram concretizados nos acordos entre o MEC e a USAID. O primeiro acordo foi firmado no dia 26 de junho de 1964, pouco mais de dois meses depois do golpe, e recebeu o nome de "Programa de Aperfeiçoamento do Ensino Primário no Brasil". Contudo, os acordos seguintes circunscreveram-se também ao ensino secundário, agrícola, industrial e superior (NOGUEIRA, 1998, p. 103). Tendo vigorado entre 1964 e 1976, os acordos envolveram, sobretudo, "cooperação técnica", isto é, remessa de infraestrutura para instalações técnicas em escolas, nada mais (p. 175). 
tecnicistas para a consecução de práticas de educação autoritárias e excludentes ${ }^{7}$. A política de equipar todas as escolas de um sistema com aparelhamento tecnológico básico é uma reivindicação pedagógica que, como se viu, data da reforma de Fernando de Azevedo nos anos 1920 e ainda não foi alcançada em sua plenitude. Não se trata, naturalmente, de negar a necessidade de que todas as escolas tenham condições de receber estrutura técnica e tecnológica, mas de exigi-la como infraestrutura básica. Insistir na renovação somente como mero aparelhamento (e nada mais), repõe aquilo que a educação brasileira tem de mais passadista: uma educação voltada inteiramente para o trabalho alienado em uma perversa e paradoxal combinação entre liberalismo e tecnicismo.

\section{A DIDÁTICA DO LIBERALISMO EDUCACIONAL TECNICISTA DA DITADURA}

Vimos, de início, como a vertente liberal-renovadora se desenhou no cenário políticosocial da Primeira República e dos primeiros anos da ditadura civil-militar. Evidenciamos o quanto esse renovadorismo facilitou as coisas para a instauração de uma doutrina tecnicista da escola no Brasil a partir da década de 1970. Doravante, abordaremos o caso desse liberalismo educacional brasileiro que facilmente se alia ao tecnicismo, produzindo como resultado final, entre outras consequências, a precarização do trabalho do professor e a perda de sua autonomia ante a organização do trabalho pedagógico.

A maioria dos manuais associa as reformas educacionais da ditadura ao projeto pedagógico tecnicista (LIBÂNEO, 1987, p. 31; SAVIANI, 1984, p. 154; 2002, p. 122), incluindo a reforma universitária, aprovada no fim do ano de 1968 com a Lei no 5.540 (BRASIL, 1968). Não raro, o reformismo dos militares foi chamado "liberal-tecnicista", a despeito de qualquer possível contradição entre os dois termos. Saviani (1985, p. 15) é coerente ao propor que a brecha encontrada pelos teóricos do tecnicismo foi a inoperância do escolanovismo, tão incapaz de resolver os problemas educacionais brasileiros quanto as pedagogias ditas tradicionais. Entre a autoridade - criticada, mas jamais abandonada - do tradicionalismo de tipo jesuíta e o discurso da inovação das tecnologias educacionais de mera aparência escolanovista, o tecnicismo encontrou o seu lugar. Sem perder de vista a base autocrática, ele se amparou no discurso da promessa de eficiência.

A reforma de 1971 nasceu no gabinete do Ministério do Planejamento e nas linhas empresarialistas do IPEA (Instituto de Pesquisas Econômicas Aplicadas). Conforme já demonstramos (OLIVEIRA, 2017, p. 22; 26-28), as mais expressivas linhas da proposta de remodelagem da escola de primeiro e segundo graus (Lei $\mathrm{n}^{\circ}$ 5.692) repousavam nas conclusões de pesquisas desenvolvidas para o Plano Decenal de Castello Branco (1964-1967). Nessas conclusões, vemos o clamor por uma educação mais técnica e menos humanista (Simonsen, 1969, p. 237). As recomendações do Plano Decenal (depois incorporadas ao Programa Estratégico do governo Costa e Silva) invocam os mesmos termos do assim chamado "texto integrado" da lei, produzido pelo Grupo de Trabalho criado por Jarbas Passarinho para formular o projeto da reforma. O texto integrado estabeleceu os princípios reformistas: integração vertical e integração horizontal, continuidade-terminalidade, flexibilidade, racionalização, gradualidade de implantação da lei, valorização do magistério e ensino supletivo (SAVIANI, 2002, p.108-112) - e foi com base nesses princípios que toda a Lei n 5.692 foi montada.

O resultado dessa reforma nacional é conhecido de todos os que estudaram a reforma de São Paulo no fim dos anos 1960: uma escola obrigatória de oito anos, integrando primário-ginásio e eliminando o exame de admissão. No primário, o elemento do trabalho era abordado pedagogicamente na forma de "sondagem de aptidões para o trabalho"; no secundário foram instituídos ginásios similares àqueles "orientados para o trabalho" e aos Pluricurriculares de São Paulo. Aos estudantes que não visassem à universidade, a formação estaria dada; eles já teriam a escolaridade mínima e poderiam ocupar o lugar de mercadoria no conjunto da força produtiva conveniente ao crescimento industrial desejado; aos interessados em uma formação complementar ou mesmo em chegar à universidade, havia o colegial - segundo ciclo do segundo grau -, de caráter profissional obrigatório. O princípio de

\footnotetext{
${ }^{7}$ Como assinalou Lima (1968, p. 11), os acordos MEC-USAID eram preferencialmente aplicados em entidades e Estados que estivessem "mais amadurecidos". São Paulo certamente se adequava a esse perfil. 
flexibilidade, exigido por Mário Henrique Simonsen a partir das resoluções do IPEA, foi servilmente colocado na lei (Oliveira, 2017, p. 27-28), de modo a favorecer a adequação das escolas particulares em relação às públicas (CUNHA, 1985, p. 67-68).

A célebre definição da profissionalização da ditadura como "profissionalização fracassada", oferecida por Cunha (1985, p. 62-72) e Germano (1993, p. 185-190), descreve com exatidão o efeito do tecnicismo brasileiro. Desde o primário (que já tinha em andamento um histórico de "exclusão pela base" $^{8}$ ) até o secundário, que a Lei $\mathrm{n}^{0} 5.692$ se encarregou de definir como ainda mais seletivo e excludente, a educação promovida pela reforma repetiu as consequências do reformismo paulistano: uma expansão e uma incorporação de alunos ao sistema escolar sem a devida ampliação técnica e física da rede, e sem o cuidado com a transformação do ensino. A valorização docente proposta pela Lei, segundo os próprios envolvidos em sua elaboração, não podia avançar no campo da conquista da autonomia - financeira ou profissional - do professor (OLIVEIRA, 2017, p. 24).

Do ponto específico da Didática (conforme a concepção de Didática dos reformadores), só poderemos encontrar alguma indicação mais acurada em defensores da Lei $n^{\circ}$ 5.692, como, por exemplo, a professora Maria de Fatima Gonçalves Castello (1974) em seu livro A didática na reforma do ensino. Em seus dois primeiros capítulos, o livro julga apresentar, respectivamente, a "filosofia da educação da reforma" e os fins almejados para o professor, cristalizados na concepção da "didática como técnica". As primeiras páginas do capítulo 1 explicam "as causas da reforma" e reencontram o argumento segundo o qual a Lei $\mathrm{n}^{\circ} 5.692$ foi necessária, porque "a situação brasileira exigia rápida modificação no ensino, sob pena de grandes desequilíbrios no mercado de trabalho e, consequentemente, em toda a economia nacional”. A antiga formação escolar produzia, segundo a professora, um aluno formado em nível colegial sem nenhuma habilidade específica para o mercado e sem lugar no espaço da universidade. Mesmo se tivesse apenas o ginasial completo, por não ter tido nenhuma formação profissional específica, ele sucumbia sem emprego na sociedade (CASTELLO, 1974, p. 2).

Ao tratar das soluções que a reforma havia dado ao impasse da educação brasileira, incapaz de atender adequadamente o mundo das mercadorias, Castello evoca o princípio didático do construtivismo de viés piagetiano definido, em parte, pelo lema "aprender a aprender", mas em chave autoritária, como se percebe a seguir.

A principal função da escola já não é promover a simples aquisição de conhecimento, mas sim ensinar a cada um como adquirir o máximo de conhecimentos com a maior economia de tempo, em suma, ensinar a cada um como estudar e como raciocinar com eficiência. (CASTELLO, 1974, p. 2-3)

Ao leitor pedagogo atento às palavras, a perspectiva de ensinar a "adquirir conhecimentos" reverbera o chamado de Piaget (1973, p. 353), em Problemas de Psicologia Genética: "o ideal da educação não é aprender ao máximo, maximizar os resultados, mas é antes de tudo aprender a aprender; é aprender a se desenvolver e aprender a continuar a se desenvolver depois da escola". Todavia, como alerta a própria parte inicial da transcrição, não se trata de "aprender ao máximo" ou de "maximizar os índices de aprendizagem", mas de ensinar ao aluno a como se desenvolver na escola e depois dela. O foco de Castello, contraditoriamente, é a busca de um "máximo de conhecimentos" no menor tempo possível, uma característica da pura pedagogia comportamentalista, cujo molde mais exato é a teaching machine de Skinner?.

\footnotetext{
${ }^{8}$ Os censos educacionais dos anos 1950 e 1960 indicam que praticamente a metade das matrículas escolares no Brasil estava registrada apenas na primeira série do primário, isto é, na série de alfabetização. As crianças, em grandes números, eram retidas logo no início da escolarização. A exclusão era, de fato, pela base. Ver apêndice preparado por Lima (1969).

9 Teaching machine (máquina de ensinar) é um aparelho idealizado por B. F. Skinner. Segundo Alves (2010, p. 35), "para ensinar por meio da instrução programada e das máquinas de ensinar, são usados os princípios do reforço. Oferece-se a informação e pede-se a execução de uma atividade a partir dela. Se o aprendiz acerta, é estimulado a continuar, recebendo novas informações; se erra, não pode avançar, mas deve voltar ao começo, até que faça corretamente o solicitado. A diferença entre a instrução programada impressa e a máquina de ensinar está no procedimento instrumental. Em vez de apresentar o comando para voltar ao começo, a máquina trava, apenas se destravando quando há acertos”. 
Assim como a atual reforma Temer do Ensino Médio, Castello (1974, p. 4) evidencia o quanto a reforma da ditadura já se pautava em organizar o currículo mantendo uma parte geral e uma parte diversificada ou específica. Ao explicar os impactos da lei sobre a escola, ela anunciava: "haverá um núcleo comum de conteúdos para cada grau" e, "em todos os currículos", "Educação moral e Cívica, Educação Física, Educação Artística, Programas de Saúde, e Ensino Religioso, este facultativo para os alunos". O "núcleo comum" será "obrigatório em todo o Brasil e fixado pelo Conselho Federal de Educação"; posteriormente, "virá uma parte diversificada", a depender das definições dos conselhos estaduais de educação, "destinadas às habilitações profissionais". Feitas essas ponderações, Castello considerou explicitados os objetivos da reforma e passou, então, ao problema de como agir tendo como meta esses objetivos. Entra em cena, então, a Didática entendida como técnica.

"A didática como técnica", título do segundo capítulo do livro de Castello, nasce de uma categorização simplista e facilitadora que separa a Pedagogia como ciência da educação e a Didática como ciência do ensino. O "ensino", estimado como "transmissão e apreensão sistemática de noções", é assim entendido como uma das formas possíveis de educação, porém, não é a única. A autora reputa desajeitadamente a ação educativa da família a uma forma de educação essencial, mas "menos sistemática que o ensino". Por que - poderíamos perguntar - a ação pedagógica familiar não pode ser inscrita enquanto forma de ensino, ainda que um ensino não sistemático como o ensino escolar? Seja como for, a Didática, para Castello (1974, p. 14), "é uma parte da Pedagogia e a ela se subordina". A Didática é ciência, arte e técnica, mas é neste último sentido que lhe interessa aprofundar. Por isso, como qualquer técnica, a Didática consiste no "conjunto de procedimentos adquiridos mediante aprendizagem sistemática e planejada" que "está sempre a serviço de um método e de uma teoria da educação" (p. 16). Entretanto, no livro de Castello a Didática não é apenas considerada como técnica da genérica organização do trabalho pedagógico, mas também do planejamento, do relacionamento, da comunicação em aula e, claro, da avaliação. Todas as dimensões da sala de aula são rigorosamente técnicas, mas nada aparece efetivamente como renovação. Se a educação apresentava um sistema que se dividia em dois sistemas distintos (o primário e o secundário, este para a escolha entre o curso colegial clássico-humanista ou o curso científico-tecnicista), com a Lei $\mathrm{n}^{\circ} 5.692$ foi no interior de um mesmo sistema que passaram a conflitar os dois perfis ainda polarizados (Saviani, 1984, p. 154). Aos interessados em prosseguir os estudos para a universidade, a parte diversificada era vencida como apêndice desimportante; ao estudante destinado ao mundo do trabalho, a escola secundária da ditadura oferecia uma formação que frequentemente não passava de puro artesanato e, por isso, vinha sempre a exigir algum curso de profissionalização posterior à escolarização básica. Foi, aliás, pelos danos causados ao próprio funcionamento da escola e da sociedade que, em 1982, o ímpeto profissionalizante fracassado foi subtraído da lei da reforma (CURY, 1982, p. 25) ${ }^{10}$.

Todos os resultados evidenciam que a reforma escolar da ditadura não conseguiu resolver o impasse da educação brasileira. O primário continuou carente de uma estruturação qualitativa e quantitativa. Desde os tempos do método Paulo Freire de alfabetização de adultos (anteriores ao golpe de 1964), as alternativas da ditadura para a eliminação do analfabetismo se frustraram. A estratégia do MOBRAL (Movimento Brasileiro de Alfabetização), por exemplo, foi corroída inteiramente, agravando as desigualdades educacionais do País (CUNHA, 1985, p. 58-59). O ensino secundário continuou elitista e voltado para um perfil propedêutico, em vista dos exames vestibulares fomentados desde o início pela ditadura, propulsionando no Brasil a "indústria do curso pré-vestibular". A universidade da ditadura, instituída em uma dinâmica burocrática infindável, passou a repousar no sistema de créditos e a tomar, quase literalmente, a forma da "educação bancária" (FREIRE, 2017, p. 87-95).

\section{A PERMANÊNCIA DO IMPASSE DA ESCOLA}

No ano de 1962, Lauro de Oliveira Lima (1970, p. 21) iniciou seu livro clássico A escola secundária moderna com o longo título que se segue:

\footnotetext{
${ }^{10}$ Ver, sobretudo, a Lei no 7.044, de 18 de outubro de 1982, que “altera dispositivos da Lei no 5.692 de 11 de agosto de 1971, referentes à profissionalização do ensino de $2^{\circ}$ grau” (BRASIL, 1982). 
A nova escola média: síntese de tendências históricas. Entre o 'ideologismo’ da Escola Intelectualista e o 'tecnologismo' da Escola Profissional, a escola média moderna optará pela objetividade reflexiva da Ciência.

$\mathrm{Na}$ atual reforma do Ensino Médio, o descompasso entre ensino bumanista e ensino tecnicista continua a existir contra a escola moderna de orientação científica, aquela que, pelo menos em tese, abrange com o mesmo vigor o desenvolvimento manual e o desenvolvimento intelectual da criança e do adolescente ${ }^{11}$. Lima (1970, p. 22), de modo pertinente e claro, aponta que a escola pode assumir como meta tanto a conservação das normas e dos valores da cultura quanto a reestruturação contínua da sociedade, e que não é o fato de a escola ser humanista ou tecnicista que determina se ela contribuirá para a conservação ou para a reestruturação da vida social. $O$ que determina isso é a "forma de abordar" os conteúdos. Se a abordagem dos conteúdos na escola se dirige à manutenção do status quo, é indiferente que tal escola seja verbalista ou tecnocrática.

$\mathrm{Na}$ reforma atual, a dualidade novamente se apresenta dessa vez entre um núcleo comum determinado por uma Base Nacional Comum Curricular (BNCC) - e itinerários formativos possíveis como complementação da formação comum. Tragicamente, como já adiantamos, a história se repete: da mesma forma que a Lei $\mathrm{n}^{\circ} 5.692$ previa uma parte comum e uma parte diversificada, a reforma atual também prevê tal divisão, nos mesmos moldes e com a mesma classe de empresários e mediadores ${ }^{12}$. Todavia, mais do que no passado, o projeto em curso se articula com a questão da avaliação e da padronização rigorosa dos processos de ensino, pois a lógica que define atualmente essa articulação é um tecnicismo novo - um neotecnicismo -, cuja ordem de eficiência obedece a modelos mais contemporâneos de produção, perfeitamente computáveis, digitalizáveis, escalonáveis e hierarquizáveis com a aparência de neutralidade positivista do sistema de ensino operado mecanicamente.

As atividades em torno da recente produção da BNCC estipularam os "objetivos da aprendizagem", válidos para todos os grupos da Educação Básica; são os chamados "direitos de aprendizagem", elaborados a partir da organização de "áreas de conhecimento". No processo de definição dos objetivos de aprendizagem, a BNCC optou pela via mais tecnicista possível: a catalogação. A linguagem com que a elaboração da BNCC se fez, a partir de códigos e siglas, é, por natureza, estranha e obscura para a Pedagogia, mas clara e cristalina para burocratas da Administração e da Economia. Para o administrador ausente do processo educativo, interessado em dados objetivos e eficientes do sistema, essa lógica permite o mais perfeito e minucioso controle da atividade docente, uma vez que converte a avaliação - com rigor computacional - em um meio de rastrear quantos e quais objetivos de aprendizagem os estudantes tiveram e - consequentemente - quantas e quais finalidades os educadores puderam alcançar com seus alunos. As escolas, por fim, também estarão à mercê de escalas e rankings. Tudo será fácil de gerenciar, rastrear, avaliar, responsabilizar, penalizar e premiar. De acordo com os reformadores, a educação brasileira poderá passar, com isso, a se enquadrar melhor nas "avaliações censitárias".

Conforme advertiu Mauro Sala (2018), a Base tem o significado de um verdadeiro "estreitamento curricular" ${ }^{13}$ que tornará irresistível "a pressão para que escolas e professores se limitem

\footnotetext{
11 O descaso da Lei no 13.415/2017 e, sobretudo, da BNCC do Ensino Médio com os conhecimentos da área de Ciências Humanas é notório. Não se trata apenas da perda considerável de espaço de saberes, como a Filosofia e a Sociologia no currículo escolar, mas do modo como o próprio elemento ético aparece na BNCC da área. Ao defender uma "educação ética", o documento ressalva que entende "ética" como "juízo de apreciação da conduta humana, necessária para o viver em sociedade, e em cujas bases destacam-se as ideias de justiça, solidariedade e livre-arbítrio (...)” (BRASIL, 2018, p. 547). As humanidades aparecem, nessa perspectiva, como elemento de ajustamento, ideia que já emergira no conceito dos Ginásios Pluricurriculares mobilizados pela ditadura. Sabemos, contudo, que a ética é algo muito além de um simplório "juízo de apreciação da conduta" e que o "livre-arbítrio" é apenas uma concepção cristã da liberdade humana, entre outras concepções possíveis.

12 Mediados pelo Conselho Nacional dos Secretários de Educação (Consed) e pela União Nacional dos Dirigentes Municipais de Educação (Undime), estão hoje agências como Fundação Itaú, Instituto Inspirare e Instituto Natura. No tempo da reforma de 1971, estavam por trás de todos os arranjos os interesses empresarialistas evocados pelo Ministério do Planejamento e pelo IPEA. Naquele tempo, também estava em atuação, igualmente, o Conselho Estadual.

13 A ênfase da reforma concentra-se somente em Língua Portuguesa e Matemática, as duas únicas matérias que serão abrangidas pela BNCC, enquanto "as outras disciplinas foram diluídas em suas áreas” (SALA, 2018). 
ao ensino do que está definido na BNCC”. Dada a compressão dos conteúdos (conhecimentos, competências e habilidades), os materiais didáticos serão produzidos com facilidade em âmbito nacional, compassados com os modelos esperados de avaliação. A indústria do tecnicismo pedagógico terá pleno impulso. $\mathrm{O}$ professor, como qualquer trabalhador que experimenta novas ondas de incremento tecnológico no sistema produtivo capitalista, tenderá a ter mais precariedade em seu trabalho e se frustrará mais em sua rotina.

A BNCC, ao longo de seu processo de construção, foi estabelecida como "obrigatória", e não como um referencial. A ideia é que, a partir dela, se padronize e se controle também a formação de professores, tanto nos cursos de Licenciatura, isto é, na formação inicial, quanto nos programas de formação continuada. Ademais, a escolarização da criança será antecipada, embora muitos educadores conheçam os efeitos nefastos desse processo. As crianças brasileiras, sobretudo as mais pobres, estarão vulneráveis à dinâmica das habilidades socioemocionais que visarão aumentar a resiliência das crianças da classe trabalhadora, resgatando o velho propósito excludente de uma sociedade escravocrata (FREITAS, 2018b).

Ao mesmo tempo, as consequências da reforma revelaram-se profundamente antidemocráticas; houve um falso alarido em torno da participação de 12 milhões de cidadãos na formulação da BNCC. Freitas (2017) desconstrói esse mito, evidenciando que o intuito dos reformadores é a aplicação do "velho estilo tecnicista que escraviza o magistério a processos previamente definidos". As consequências desse projeto, estabelecido também em outros países, revelam a "desqualificação e culpabilização tanto do magistério como da própria escola pública de gestão pública". Além disso, sabemos que a Base edificada pela Nova Zelândia, por exemplo, vem sendo eliminada por não corresponder à materialidade do processo educativo (FREITAS, 2018a).

Infelizmente, do ponto de vista da inovação na organização curricular da escola e da sala de aula, a BNCC nada apresentou. Os hodiernos processos tecnológicos da lógica gerencialista repetem a mesma perspectiva dos processos técnicos propostos pela reforma escolar da ditadura. Na verdade, o ideal da Didática como ciência do ensino e como técnica pedagógica de Castello (1974) realiza-se plenamente na atual reforma, pois em 2017 chegamos ao ápice do controle e da padronização que a professora da ditadura desejava para os "técnicos de ensino" ou professores de seu tempo. A pretensão de avaliação, hierarquização e escalonamento por mérito, a ser aplicada atualmente a alunos, professores e escolas, consiste em fechar a trama que nos anos 1970 ficou em aberto. Sob o pretexto de atualizar a educação nacional, retornamos fatalmente ao velho jesuitismo.

Lembremos que no século XVI chegaram ao Brasil os jesuítas, membros da Companhia de Jesus, uma espécie de "fundação", como nos esclarece a singularíssima interpretação de Lima (1974, p. 27): uma "organização privada a que o rei dava poderes de empresa pública autônoma". Os jesuítas "montaram, quase clandestinamente, uma 'rede escolar' (...) de caráter estritamente profissional (preparação de clérigos e de amanuenses para a colônia das Companhias de Comércio e Navegação)", uma "rede" limitada que "provavelmente nunca deve ter alcançado, mesmo em seu auge, número superior a três mil alunos" (p. 23). A Companhia, conforme estudos mais recentes acentuam, desenvolvia atividades primordialmente comerciais: ela "se distingue muito mais pelo seu caráter colonizador e mercantil do que por uma ação simplesmente missionária ou pedagógica" (LINS, 2003, p. 66-67). A escola jesuíta, ao contrário do que se ensina tradicionalmente, sempre favoreceu os interesses da burguesia colonial, cujo intuito não era "escolarizar" os "silvícolas", mas apenas doutrinálos para o trabalho (p. 64). Jorge Benci foi um dos maiores expoentes do mercantilismo, autor de um verdadeiro tratado burguês da sociedade brasileira escravocrata - a Economia cristã dos senhores no governo dos escravos (1700). Nesse livro ele põe em cena o lema maior da orientação pedagógica para a exploração do trabalho servil: "ao servo: pão, ensino e trabalho" ("panis, et disciplina, et opus servo"). O discurso de Benci, profundamente analisado por Lins (2003, p. 9), permite concluir que "a negação da escola para a classe trabalhadora, nos séculos XVI, XVII e XVIII, está diretamente relacionada com a necessidade histórica de braços para as manufaturas". Assim foi também com a reforma escolar da ditadura: a lei se fazia necessária para formar a mão de obra barata promotora da máquina do crescimento industrial que deu renome ao milagre econômico brasileiro (OLIVEIRA, 2017, p. 20). 
Aos reformadores - liberais-renovadores ou liberais-tecnicistas - nada parece mais estranho do que atribuir a pecha de "jesuítas", afinal, eles, sempre que puderam, criticaram o ideal da formação da Companhia de Jesus, tomando-o como mero adestramento ou como ensino exageradamente humanista — discursos comuns aos economistas da educação da década de 1960 e 1970, como Mário Henrique Simonsen e Roberto Campos, e aos renovadores-liberais do grupo de Fernando de Azevedo ou Anísio Teixeira. O jesuitismo desenvolveu preponderantemente no Brasil um trabalho mercantil, e sua escolarização não passava, na verdade, de uma tentativa de profissionalização em estilo tecnicista, comparável, aliás, ao sentido mais moderno, conquanto sua abordagem de conteúdos tenha sido mantida sempre verbalista e intelectualista.

Marilena Chaui esclarece bem o quão falso é o dilema que se impõe no senso comum pedagógico, de acordo com o qual bumanismo e tecnicismo são estimados como polos opostos de orientação docente. $\mathrm{Na}$ verdade, explica ela, o humanismo e a tecnocracia são dois lados da mesma moeda da educação burguesa, "pois o homem tanto como fim (Kant, Mounier) quanto como meio (Skinner, Taylor) é uma abstração" (CHAUI, 2016, p. 254). No Brasil, o humanismo residual permanente, o liberalismo de aparências e o tecnicismo autoritário se imiscuem e se justapõem para manter a Didática tal como sempre foi.

\section{A DIDÁTICA E A CONTÍNUA DISTORÇÃO TECNICISTA}

Lima (1974, p. 211) inicia o décimo capítulo de Estórias da educação no Brasil afirmando, de forma galhofeira, que a Lei $n^{\circ} 5.692$ representaria a "derrota final dos jesuítas", esses professores que tentamos expulsar dos quadros da pedagogia brasileira desde Pombal. Mas a atual reforma no campo da Didática repõe, pela BNCC aprovada, aquele mesmo procedimento jesuíta da Ratio Studiorum: uma organização de estudos por regras, ditames e advertências que todos os envolvidos no processo pedagógico devem ler, entender e aplicar, a ponto de ser possível a posteriori tanto premiar os que se destacam no regime meritocrático, quanto penalizar os que nele se frustram. Com o véu da vanguarda, a BNCC antidemocraticamente estabelecida se converte em um padrão inevitável, extinguindo a autonomia docente com uma veemência que faz lembrar, por mais incoerente que pareça ser, a Ratio da Companhia. Se na colônia a abordagem foi à maneira jesuíta, em atendimento ao apelo de mão de obra escravizada para a monocultura, na reforma escolar da ditadura e na atual, a abordagem é, respectivamente, tecnicista e neotecnicista.

Os efeitos nefastos da combinação entre o liberal e o tecnicista seriam, por acaso, fenômeno recente? Longe disso. Jorge Nagle, novamente, com a habilidade e profundidade de seu trabalho, nos alertava, desde 1966, quanto aos riscos do que chamou de "distorção técnica". Segundo ele, as reformas de 1920 em São Paulo, assim como outras tantas, cederam a uma intrusão de elementos técnicos que ganhavam seu espaço e obstavam seu pleno êxito, viabilizando um "desvio aparatoso". Em suas palavras, "ao destacar e superestimar determinados aspectos técnicos da escolarização, o movimento escolanovista deslocou o enfoque fundamentalmente político que a questão da educação popular tivera até então". Com isso, completa o eminente professor, houve uma radical mudança de sentido nas propostas reformistas renovadoras: deu-se a "gradual substituição da dimensão política pela dimensão técnica" (NAGLE, 2009, p. 284).

A repetição de reformas como as que assistimos no Brasil republicano é uma constante que adia e afasta, de tempos em tempos, a urgência de uma revolução do ensino no Brasil ${ }^{14}$. Fica à espera a

\footnotetext{
${ }^{14}$ Uma revolução do ensino, sob a perspectiva histórica da análise aqui desenvolvida, requer antes de tudo a construção de uma escola que articule as dimensões humanas e técnicas da formação, entretecendo-as em uma espécie de "instrução integral", como escreveram os socialistas do fim do século XIX e do começo do século XX. O modelo desses socialistas, concebido diante dos desafios tecnológicos de hoje, implica uma oposição frontal a este incansável impasse. A perspectiva didática revolucionária não poderá fazer da técnica a mera distorção de uma educação falsamente humanista, nem do humanismo uma formação elitizada, concebida pelo viés da ciência burguesa, sempre aberta a ser distorcida pela tecnocracia. Nesse sentido, a reflexão sobre a prática de ensino e a organização do trabalho pedagógico poderá encontrar respaldo na atualização de teses como as de Moysei Pistrak (1888-1940) e Francisco Ferrer (1859-1909). Nos domínios conceituais da Educação em Revista|Belo Horizonte |v.36|e220281|2020
} 
realização daquele ideal que Nagle (1973, p. 27) almejou para a Lei $n^{\circ}$ 5.692: a produção de um sistema escolar que "encontra no próprio dinamismo os recursos para sua contínua reformulação". Mantém-se ainda em suspenso o projeto principal da revolução educacional de que o País necessita: uma reforma que "promove, por si mesma, contínuas reformas" (LIMA, 1974, p. 267).

\section{REFERÊNCIAS}

ALVES, Maria Leila. Considerações sobre a influência de Skinner na educação brasileira. In: SMITH, Louis (org.) Burrhus Skinner. Tradução: Maria Leila Alves. Recife: Fundação Joaquim Nabuco/Editora Massangana, 2010, p. 29-44.

AZANHA, José Mário Pires. Alguns escritos. São Paulo: Companhia Editora Nacional, 1987.

AZEVEDO, Fernando de. A transmissão da cultura. São Paulo: Melhoramentos; Brasília: INL, 1976.

AZEVEDO, Fernando de. O manifesto dos pioneiros da educação nova. Revista HISTEDBR, n. especial, p. 188-204, 2006.

BELTRÃO, Ierecê. Corpos dóceis, mentes vazias, corações frios. Didática: o discurso científico do disciplinamento. São Paulo: Imaginário, 2000.

BRASIL. Lei Federal n ${ }^{\circ}$ 4.024, de 20 de dezembro de 1961. Fixa as Diretrizes e Bases da Educação Nacional. Diário Oficial da União, Brasília, DF, p. 11429, 27 dez. 1961.

BRASIL. Lei Federal n ${ }^{\circ}$ 5.540, de 28 de novembro de 1968. Fixa normas de organização e funcionamento do ensino superior e sua articulação com a escola média, e dá outras providências. Diário Oficial da União, Brasília, DF, p. 10433, 3 dez. 1968.

BRASIL. Lei Federal no 5.692, de 11 de agosto de 1971. Fixa Diretrizes e Bases para o ensino de $1^{\circ}$ e $2^{\circ}$ graus, e dá outras providências. Diário Oficial da União, Brasília, DF, p. 6377, 12 ago. 1971.

BRASIL. Lei Federal no 7.044, de 18 de outubro de 1982. Altera dispositivos da Lei 5.692/71, referentes à profissionalização do ensino de $2^{\circ}$ grau. Diário Oficial [da República Federativa do Brasil], Brasília, DF, 19 out. 1982. In: BRASIL. Ministério da Educação e Cultura. Coletânea da legislação da educação e cultura: 1981-1982. Brasília: MEC, 1982.

BRASIL. Lei Federal no 13.415, de 16 de fevereiro de 2017. Altera as Leis no ${ }^{\circ} 9.394$, de 20 de dezembro de 1996, que estabelece as diretrizes e bases da educação nacional, e 11.494, de 20 de junho 2007, que regulamenta o Fundo de Manutenção e Desenvolvimento da Educação Básica e de Valorização dos Profissionais da Educação, a Consolidação das Leis do Trabalho - CLT, aprovada pelo Decreto-Lei $n^{\circ} 5.452$, de $1^{\circ}$ de maio de 1943, e o Decreto-Lei n ${ }^{\circ} 236$, de 28 de fevereiro de 1967; revoga a Lei $n^{\circ}$ 11.161, de 5 de agosto de 2005; e institui a Política de Fomento à Implementação de Escolas de Ensino Médio em Tempo Integral.

BRASIL. Base Nacional Comum Curricular - Ensino Médio. Brasília: Ministério da Educação, 2018.

CAMINHA, Adolfo. A normalista. Rio de Janeiro: Magalhães, 1893.

Didática pensada contemporaneamente no Brasil, o trabalho de Beltrão (2000) é o que mais se aproxima da busca de uma prática de ensino mais atenta aos riscos do controle técnico e disciplinar da formação. 
CASTELLO, Maria de Fátima. A didática na reforma do ensino. Rio de Janeiro: Francisco Alves, 1974.

CHAUI, Marilena. Ideologia e educação. Educação e Pesquisa, v. 42, n. 1, p. 245-257, 2016.

CUNHA, Luiz Antonio. Roda-viva. In: CUNHA, Luiz Antonio; GÓES, Moacyr de. O golpe na educação. Rio de Janeiro: Zahar, 1985, p. 35-90.

CURY, Carlos Jamil. A profissionalização do ensino médio na Lei no 5.692/71. Brasília: INEP, 1982.

CURY, Ariam. Azanha e a democratização do acesso ao ensino. 2012. Dissertação (Mestrado em Educação). Universidade de São Paulo - USP, São Paulo, SP.

DISTRITO FEDERAL. Decreto no 3.281, de 23 de janeiro de 1928. Reforma do Ensino no Distrito Federal. Prefeitura do Distrito Federal, Rio de Janeiro, Oficinas Gráficas do Jornal do Brasil, 1928.

FERREIRA, Daniela. Ginásio Vocacional "Cândido Portinari” de Batatais: histórias, sujeitos e práticas. 2007. Dissertação (Mestrado em Educação). Universidade de São Paulo - USP, São Paulo, SP.

FREIRE, Paulo. Educação como prática da liberdade. 26a edição. São Paulo: Paz e Terra, 2002.

FREIRE, Paulo. Pedagogia do oprimido. 63a edição. Rio de Janeiro/São Paulo: Paz e Terra, 2017.

FREITAS, Luiz Carlos de. BNCC: o mito dos 12 milhões de participantes, 03 dez. 2017. Disponível em: https://avaliacaoeducacional.com/2017/12/03/bncc-o-mito-dos-12-milhoes-de-participantes Acesso em: 05 abr. 2018.

FREITAS, Luiz Carlos de. Dia D da BNCC: doze razões para não ser coadjuvante, 05 mar. 2018 a. Disponível em: https://avaliacaoeducacional.com/2018/03/05/dia-d-da-bncc-12-razoes-para-nao-sercoadjuvante Acesso em: 05 abr. 2018.

FREITAS, Luiz Carlos de. A BNCC e a "salvação" dos pobres pela resiliência, 08 mar. 2018b. Disponível em: https://avaliacaoeducacional.com/2018/03/08/a-bncc-e-a-salvacao-dos-pobres-pelaresiliencia Acesso: 05 abr. 2018.

GANDINI, Raquel. Tecnocracia, capitalismo e educação em Anísio Teixeira. Rio de Janeiro: Civilização Brasileira, 1980.

GERMANO, José. Estado militar e educação no Brasil (1964-1985). São Paulo: Cortez; Campinas: Editora da Unicamp, 1993.

LIBÂNEO, Carlos. Democratização da escola pública. São Paulo: Loyola, 1987.

LIMA, Lauro de Oliveira. Prefácio. In: ALVES, Márcio. Beabá dos MEC-USAID. Rio de Janeiro: Gernasa, 1968, p. 7-15.

LIMA, Lauro de Oliveira. O impasse na educação. Petrópolis: Vozes, 1969.

LIMA, Lauro de Oliveira. A escola secundária moderna. Petrópolis: Vozes, 1970. 
LIMA, Lauro de Oliveira. Estórias da educação no Brasil: de Pombal a Passarinho. Brasília: Editora Brasília, 1974.

LINS, Ana Maria Moura. Educação moderna: contradições entre o projeto civilizatório burguês e as lições do capital. Campinas: Autores Associados, 2003.

NAGLE, Jorge. A reforma e o ensino. São Paulo: Edart, 1973.

NAGLE, Jorge. Educação e sociedade na Primeira República. São Paulo: Edusp, 2009.

NOGUEIRA, Francis. Ajuda externa para a educação brasileira na produção do mito do desenvolvimento: da USAID ao BIRD. 1998. Tese (Doutorado em Educação). Universidade Estadual de Campinas - UNICAMP, Campinas, SP.

NUNES, Clarice. Escola \& dependência: o ensino secundário e a manutenção da ordem. Rio de Janeiro: Achiamé, 1980.

OLIVEIRA, Fernando Bonadia de. Entre reformas: tecnicismo, neotecnicismo e educação no Brasil.

RETTA, Rio de Janeiro, n. 16, p. 19-39, jul./dez. 2017.

PIAGET, Jean. Problemas de psicologia genética. Tradução: Célia Di Piero. Rio de Janeiro: Forense, 1973.

SALA, Mauro. Para onde aponta a BNCC para o Ensino Médio?, 28 fev. 2018. Disponível em: http:/ / www.esquerdadiario.com.br/Para-onde-aponta-a-Base-Nacional-Comum-Curricular-para-oEnsino-Medio Acesso em: 06 abr. 2018.

SÃO PAULO (Estado). Lei no 1.750, de 8 de dezembro de 1920. Reforma a instrução pública do Estado. Diário Oficial do Estado de São Paulo, São Paulo, 11 dez. 1920, p. 7657.

SAVIANI, Dermeval. Educação: do senso comum à consciência filosófica. São Paulo:

Cortez/Autores Associados, 1984.

SAVIANI, Dermeval. Escola e democracia. São Paulo: Cortez, 1985.

SAVIANI, Dermeval. Política e educação no Brasil. Campinas-SP: Autores Associados, 2002.

SIMONSEN, Mario Henrique. Brasil 2001. Rio de Janeiro: APEC, 1969.

SOUZA, Paulo Nathanael. O Ginásio Único Pluricurricular de São Paulo. São Paulo: Companhia Editora Nacional, 1970.

Submetido: $20 / 02 / 2019$

Aprovado: 18/10/2019 